\title{
DEPRESSION AND ANXIETY AMONG PATIENTS SEEKING RHINOPLASTY
}

\author{
Sikandar Ali Khan, Ghazanfar Ali, Maqbool Raza, Muhammad Tariq*, Imran Adeel**, Ahsan Masood Butt \\ Combined Military Hospital Multan/National University of Medical Sciences (NUMS) Pakistan, *Combined Military Hospital Jehlum/National University of \\ Medical Sciences (NUMS) Pakistan, **Bahawalpur Victoria Hospital, Bahawalpur Pakistan
}

\begin{abstract}
Objective: To evaluate the presence and relation of depression and anxiety among patients seeking rhinoplasty Study Design: A cross-sectional study.

Place and Duration of Study: Departments of Psychiatry, department of Plastic Surgery and ENT, Combined Military Hospital Multan, from Jan 2019 to Mar 2020.

Methodology: A total of 102 patients were recruited that reported to Plastic surgery and ENT unit. Patients were divided equally in two groups of 51 each. One group included patients seeking rhinoplasty while other group included those patients that reported in Plastic surgery and ENT unit for reasons other than rhinoplasty. Symptom were assessed using Beck Depressive Inventory for depression and Beck Anxiety Inventory for anxiety.

Results: A total of 102 participants were included in the study, of these 51 were patients seeking rhinoplasty and 51 were controls. Significant correlation exist between anxiety and depression $(p<0.00)$.

Conclusion: There is a very high frequency of anxiety and depression among patients seeking Rhinoplasty along with significant positive correlation.
\end{abstract}

Keywords: Anxiety, Depression, Rhinoplasty.

How to Cite This Article: Khan SA, Ali G, Raza M, Tariq M, Adeel I, Butt AM. Depression and Anxiety Among Patients Seeking Rhinoplasty. Pak Armed Forces Med J 2021; 71 (Suppl-3): S594-597. Doi: https://doi.org/10.51253/pafmj.v1i1.5507

This is an Open Access article distributed under the terms of the Creative Commons Attribution License (https://creativecommons.org/licenses/by-nc/4.0/), which permits unrestricted use, distribution, and reproduction in any medium, provided the original work is properly cited.

\section{INTRODUCTION}

The desire to strive for facial beauty is not surprising that cosmetic and functional rhino/septoplasty (RSP) ranks among the most commonly performed surgical procedures all over the world. ${ }^{1}$ Psychological impact is more profound to rhinoplasty than it is to other facial plastic surgical procedures, because patients seeking other plastic surgery procedures are simply in pursuit of a return to a previously favorable self-image on the other hand rhinoplasty patients have been living with the insecurity of their nose as a formative part of their body image. ${ }^{2}$ These patients are more apprehensive about the options and proposals given by plastic surgeons as they often have a preferred self-image in their mind but are unable describe that image, ${ }^{3}$ Presence of Psychiatric disorder is one of the predictors of poor outcome in cosmetic plastic surgery patients. ${ }^{4}$ In today's era media projects ideal physical images that leads to discord between actual physical appearance of individual and mental ideal image consequently it leads to dissatisfaction and request for physical change rather than change in mental image. ${ }^{5}$ Commonly people seek rhinoplasty for uplift of their facial features in order to reduce their distress and discord between actual physical appearance and ideal mental image. ${ }^{6}$

Correspondence: Dr Sikandar Ali Khan, Department of Psychiatry, Combined Military Hospital, Multan Pakistan
Dissatisfaction with body image can lead to depression, ${ }^{7}$ anxiety and poor psychological adaptation to changes brought by surgery. ${ }^{8}$ Studies have shown that even a subtle change in appearance of a person can influence others behaviors. This interplay between perceiver and patient leads to incorporation of perceivers expectations into mental image which if not in accord with actual physical appearance it will lead to negative impact on patient in the form of anxiety, depression and social avoidance. ${ }^{9}$

This study was planned to assess relationship between presence of depression and anxiety among patients seeking cosmetic surgical procedure of rhinoplasty. Surgeons are not Psychiatrist or psychologists therefore results of this article will help surgeons to appreciate the psychiatric aspect of cosmetic surgery and will help in early detection of any psychiatric illness to facilitate appropriate management and better outcome.

\section{METHODOLOGY}

This cross-sectional study was conducted at the department of Psychiatry, Combined Military Hospital Multan in liaison with the department of plastic surgery and ENT department from January 2019 to March 2020. A sample size of 102 was estimated via EpiTools Epidemiological Calculator while keeping level of significance $5 \%$, confidence level $95 \%$, estimated true 
proportion $63 \%$ based on the observation made in the study by Marx, and $5 \%$ of absolute precision. ${ }^{10}$ Total number of sample size was equally matched and divided into two groups of fifty one. One group of fifty one participants represented those who were seeking rhinoplasty as cosmetic surgery. Second group of fifty one participants included those who were getting consultation from surgeon for other reasons. Both groups of 51 were assessed for anxiety and/or depression based on the diagnostic criteria of International Classification of Diseases version 10 after approval from the hospital ethical committee. All inductees were interviewed after the informed written consent and their confidentiality was ensured. Individuals with other disabling diseases and past psychiatric history were not included.

Demographic details of the inductees were documented. Detailed assessment and symptom were assessed using Beck Depressive Inventory (BDI) for depression and Beck Anxiety Inventory (BAI) for anxiety.11,12 BDI consists of 21 questions, each with four possible answers that are assigned a score ranging from 0-3. Higher scores indicate more severe symptoms. Total score is obtained by adding individual scores of 21 items and total score ranges from 0-63. The cut off score for presence of symptoms is. ${ }^{9}$ It may be noted that $\mathrm{BDI}$ is for detecting depressive symptoms and not for diagnosing depression. BAI consists of 21 items, scored on Likert-type scale from 0-3 where 0 is considered negative, 1 is judged as mild, 2 is deemed moderate, and 3 is considered severe. The cut off score for presence of symptoms is. ${ }^{15}$ Descriptive statistics like mean with standard deviation was calculated for age. Frequency along with percentages was calculated for socio-demographic variables.

Data analysis was performed using Statistical Package for Social Sciences (SPSS) version 20. The data were described as numbers and percentages. For association and comparison Pearson's chi square test was used. All the inferences were made at $95 \%$ confidence interval and $p$-values of $\leq 0.05$ were considered significant.

\section{RESULTS}

A total of 102 participants were included in the study, of these 51 were patients seeking rhinoplasty and 51 were controls. The mean ages were $25.6 \pm 6.59$ years and $28.2 \pm 7.79$ years for rhinoplasty group and control group respectively. Most of the participants in both groups were single, educational status and employment status is shown in Table-I. Anxiety was present in $25(48 \%)$ patients of rhinoplasty group as compared to $13(28 \%)$ patients of control group as shown on figure. Depression was present in $15(30 \%)$ patients of rhinoplasty group as compared to $10(19 \%)$ patients of control group (Table-I).

Table-I: Distribution of demographic variables.

\begin{tabular}{|c|c|c|}
\hline & $\begin{array}{c}\text { Rhinoplasty } \\
\text { Group } \mathrm{n}=51(\%)\end{array}$ & $\begin{array}{c}\text { Control Group } \\
n=51(\%)\end{array}$ \\
\hline Age (Mean \pm SD) & $25.6 \pm 6.59$ & $28.2 \pm 7.79$ \\
\hline \multicolumn{3}{|l|}{ Gender } \\
\hline Male & $5(10.1)$ & $10(19.3)$ \\
\hline Female & $46(89.8)$ & $41(80.6)$ \\
\hline \multicolumn{3}{|l|}{ Marital Status } \\
\hline Single & $42(81.7)$ & $36(70.4)$ \\
\hline Married & $7(14.5)$ & $14(27.2)$ \\
\hline Divorced & $2(3.6)$ & $1(2.2)$ \\
\hline \multicolumn{3}{|c|}{ Educational Status } \\
\hline Primary & $5(9.4)$ & $4(8.1)$ \\
\hline Secondary & $9(18.2)$ & $11(21.5)$ \\
\hline Under graduate & $29(57.3)$ & $34(68.3)$ \\
\hline Graduate & $8(14.8)$ & $2(1.8)$ \\
\hline \multicolumn{3}{|c|}{ Occupational Status } \\
\hline Employed & $11(21.2)$ & $15(29.6)$ \\
\hline Un-employed & $40(78.7)$ & $36(73.3)$ \\
\hline \multicolumn{3}{|l|}{ Mental Health } \\
\hline Anxiety & $25(48)$ & $13(25)$ \\
\hline Depression & $15(30)$ & $10(19)$ \\
\hline
\end{tabular}

After evaluating statistical correlation of anxiety and depression in rhinoplasty and control group, a significant correlation was found with both anxiety and depression $(p \leq 0.001)$ (Table-II) on the other hand educational status $(p=0.23)$ and marital status $(p=$ $0.193)$ was not found to be significantly correlated (Table-III).

Table-II: Anxiety and depression with relation to rhinoplasty and control groups.

\begin{tabular}{l|c|c|c}
\hline Group & $\begin{array}{c}\text { Anxiety } \\
\mathbf{n}(\%)\end{array}$ & $\begin{array}{c}\text { Depression } \\
\mathbf{n}(\%)\end{array}$ & $\begin{array}{c}p \text { - } \\
\text { value }\end{array}$ \\
\hline $\begin{array}{l}\text { Rhinoplasty } \\
\text { Group }\end{array}$ & $25(48)$ & $15(30)$ & \multirow{2}{*}{$<0.001$} \\
\cline { 1 - 2 } Control Group & $13(25)$ & $10(19)$ & \\
\hline
\end{tabular}

Table-III: Educational status and marital status with relation to Rhinoplasty with Control group.

\begin{tabular}{|c|c|c|c|c|c|c|c|c|c|}
\hline \multirow[b]{2}{*}{ Group } & \multicolumn{4}{|c|}{ Educational Status, n (\%) } & \multirow[b]{2}{*}{$\begin{array}{c}p- \\
\text { value }\end{array}$} & \multicolumn{3}{|c|}{ Marital Status, n (\%) } & \multirow[b]{2}{*}{$\begin{array}{c}p- \\
\text { value }\end{array}$} \\
\hline & Primary & Secondary & $\begin{array}{c}\text { Under } \\
\text { Graduate }\end{array}$ & Graduate & & Single & Married & $\begin{array}{c}\text { Divorced/W } \\
\text { idow }\end{array}$ & \\
\hline $\begin{array}{l}\text { Rhinoplasty } \\
\text { group }\end{array}$ & $5(9.4)$ & $9(18.2)$ & $29(57.3)$ & $8(14.8)$ & \multirow[t]{2}{*}{0.230} & $42(81.7)$ & $7(14.5)$ & $2(3.6)$ & \multirow[t]{2}{*}{0.193} \\
\hline Control group & $4(8.1)$ & $11(21.5)$ & $34(68.3)$ & $2(1.8)$ & & $36(70.4)$ & $14(27.2)$ & $1(1.2)$ & \\
\hline
\end{tabular}




\section{DISCUSSION}

This study was done to highlight the presence of Anxiety and Depression that is present in significant number of patients who seek Rhinoplasty. While devising a management plan for those seeking rhinoplasty it is important to incorporate thorough assessment of mental health as it has lasting impact on the outcome of surgery. ${ }^{13}$

Results of this study are consistent with other studies as majority of patients seeking rhinoplasty were young, single females. Similar results were observed in studies done by Abbas, ${ }^{14}$ de Brito, ${ }^{15}$ and Bouman, ${ }^{16}$ in which there was higher prevalence of females seeking rhinoplasty as they are preoccupied with physical appearance of their breast, hip with particular focus on skin tone, color, hairs or shape of nose, ${ }^{17}$ as compared to males who are more concerned about their body hairs, genital and height. ${ }^{18}$ In this study $50 \%$ of females were employed as compared to the study done by Aguila in which $76 \%$ of the females were employed this difference is indicative of cultural difference. ${ }^{19}$

Subjective distress and impairment of psychosocial functioning due to physical appearance warrants psychological evaluation of patients seeking rhinoplasty. ${ }^{20}$ These patients are depressed, anxious and constantly remain preoccupied with the physical image that is not in accordance with the mental image of their body. ${ }^{21}$ Aguila in her study reported that $45 \%$ of patients seeking rhinoplasty had depression while $92 \%$ had average anxiety as it can be seen in this study where number of patients having anxiety is higher than those who exhibited depression. ${ }^{18}$ Similarly Kucur et al has observed that anxiety and depression scores among patients seeking rhinoplasty were higher than control group. ${ }^{22}$ Results of this study also show that Anxiety was $48 \%$ while Depression was $30 \%$ in patients seeking rhinoplasty as compared to control group where anxiety was $25 \%$ and depression in $19 \%$ of patients, but contrary to these results Benjamin Jane in their study have shown higher prevalence of depression (50.6\%) as compared to anxiety (32.9) among patients undergoing cosmetic surgery. ${ }^{23}$

In the study by Ghahremani et al, it was observed that significant correlation was found among age, gender, marital status and job and that complaints of anxiety and depression was higher among female patients seeking rhinoplasty. ${ }^{24}$ Similarly study by Strazdins found significant correlation between age, gender, marital status, occupation and psychological characteristics in patients seeking cosmetic surgery. ${ }^{21}$ In this study although presence of Anxiety and depression among patients seeking rhinoplasty is significantly higher but contrary to other studies there is no significant correlation between and educational status, marital status and psychological complaints in patients seeking rhinoplasty.

\section{RECOMMENDATIONS}

Psychiatric assessment of patients seeking rhinoplasty should be routine practice for detection and proper management of anxiety and depression in these patients.

\section{CONCLUSION}

Cosmetic surgeons are not Psychiatrist or Psychologist but they are faced with patients who have a very high prevalence of anxiety and depression while they seek rhinoplasty. This study has highlighted the importance of early detection and timely management of anxiety and depression in patients seeking rhinoplasty as its early detection has tremendous impact on post-surgical outcome. This can only be done with realization, early identification, close co-ordination and early involvement of psychiatrist for proper management of anxiety and depression in patients seeking rhinoplasty.

\section{Conflict of Interest: None.}

\section{Authors' Contribution}

SAK: Data collection, compilation and discussion, GA: Data collection and interpertation, MR: Archive data search, MT: Data entry and statistical analysis, IA: Data analysis, AMB: proof reading and compilation

\section{REFERENCES}

1. Kopacheva-Barsova G, Nikolovski N, Arsova S, Kopachev D. Psychological patient reactions after septorhinoplasty-our personal view. OA Maced J Med Sci 2015; 3(4): 635-639.

2. Davis RE, Bublik M. Psychological considerations in the revision rhinoplasty patient. Facial Plastic Surg 2012; 28(4): 374-379.

3. Lu SM, Hsu DT, Perry AD, Leipziger LS, Kasabian AK, Bartlett SP, et al. The public face of rhinoplasty: impact on perceived attractiveness and personality. Plastic Reconstruct Surg 2018; 142(4): 881-887.

4. Jang B, Bhavsar DR. The prevalence of psychiatric disorders among elective plastic surgery patients. Eplast 2019; 19(6): 1-5.

5. Woods SL. Implications of diverse peer interactions on body image satisfaction and cosmetic surgery acceptance among college students. 2016; 2(1): 1-6.

6. Heyes CJ, Latham JR. Trans surgeries and cosmetic surgeries: The politics of analogy. TSQ 2018; 5(2): 174-189.

7. Monpellier VM, Antoniou EE, Mulkens S, Janssen IM, van der Molen AB, Jansen AT. Body image dissatisfaction and depression in postbariatric patients is associated with less weight loss and a desire for body contouring surgery. Surg Obes Relat Dis 2018; 14(10): 1507-1515.

8. Ryding FC, Kuss DJ. The use of social networking sites, body image dissatisfaction, and body dysmorphic disorder: A systematic review of psychological research. Psychol Popul Med Cul 2020; 9(4): 412-435.

9. Lee $\mathrm{HH}$, Moon $\mathrm{H}$. The effects of media and self-image congruity of ideal body image on dieting and exercising behaviors-Comparison of Korea and US female college students. Res J Cost Cul 2018; 26(5): 806-821. 
10. Marx W, McCarthy AL, Ried K, McKavanagh D, Vitetta L, Sali A, et al. The effect of a standardized ginger extract on chemotherapy-induced nausea-related quality of life in patients undergoing moderately or highly emetogenic chemotherapy: a double blind, randomized, placebo controlled trial. Nutrient 2017; 9(8): 867.

11. Beck AT, Steer RA, Brown G. Beck depression inventory-II. Psychol Assessm 1996, Available from: https://doi.org/10.1037/ t00742-000.

12. Steer RA, Beck AT. Beck Anxiety Inventory. Evaluating stress: A book of resources 1997, [Internet] Available at: https:// psycnet.apa.org/record/1997-09146-002

13. Strazdins E, Nie YF, Ramli R, Palesy T, Christensen JM, Marcells GN, et al. Association of mental health status with perception of nasal function. JAMA Facial Plastic Surg 2017: 5(2): 369-377.

14. Abbas OL, Kurkcuoglu A, Aytop CD, Uysal C, Pelin C. Perception of symmetry in aesthetic rhinoplasty patients: Anthropometric, demographic, and psychological analysis. Percep 2017; 46(10): 1151-1170.

15. de Brito MJ, Nahas FX, Cordás TA, Tavares H, Ferreira LM. Body dysmorphic disorder in patients seeking abdominoplasty, rhinoplasty, and rhytidectomy. Plast Reconst Surg 2016; 37(2): 462-471.

16. Bouman TK, Mulkens S, van der Lei B. Cosmetic professionals' awareness of body dysmorphic disorder. Plastic Reconst Surg 2017; 139(2): 336-42.
17. Franca K, Roccia MG, Castillo D, AlHarbi M, Tchernev G. Body dysmorphic disorder: history and curiosities [ahead of print since 2017]. Wien Med Woch 2017; 167(Suppl-1): 5-7.

18. Anderson RC. Body dysmorphic disorder: recognition and treatment. Plast Surg Nurs 2003; 23(3): 125-129.

19. Del Aguila E, Martínez JR, Pablos JL, Huánuco M, Encina VM, Rhenals AL. Personality traits, anxiety, and self-esteem in patients seeking cosmetic surgery in mexico city. Plast Reconstr Surg Glob Open 2019; 7(10): e2381.

20. Brito MJ, Sabino Neto M, de Oliveira MF, Cordás TA, Duarte LS, Rosella MF, et.al. Yale-Brown obsessive compulsive scale modified for body dysmorphic disorder (BDD-YBOCS): Brazilian Portuguese translation, cultural adaptation and validation. Rev Bras Psiquiatr 2015; 37(4): 310-316.

21. Ziglinas P, Menger DJ, Georgalas C. The body dysmorphic disorder patient: to perform rhinoplasty or not? Eur Arch Otorhinolaryngol 2014; 271(9): 2355-2358.

22. Kucur C, Kuduban O, Ozturk A, Gozeler MS, Ozbay I, Deveci E, et al. Psychological evaluation of patients seeking rhinoplasty. Eurasian J Med 2016; 48(2): 102.

23. Ghahremani L, Motevasel M, Fararooei M, Rakhshani T. Mental health in rhinoplasty applicants, before and after surgery. Archives of Psych Psychoth 2019; 4(2): 45-51.

24. Higgins S, Wysong A. Cosmetic surgery and body dysmorphic disorder-An update. Inter J Women's Dermatol 2018; 4(1): 43-48. 